\title{
BMJ Open Exploring the concept of pain of Australian children with and without pain: qualitative study
}

\author{
Joshua W Pate (D) , ${ }^{1}$ Tim Noblet, ${ }^{1}$ Julia M Hush, ${ }^{1}$ Mark J. Hancock, ${ }^{1}$ \\ Renee Sandells, ${ }^{2}$ Meg Pounder, ${ }^{2}$ Verity Pacey ${ }^{1,3}$
}

To cite: Pate JW, Noblet T, Hush JM, et al. Exploring the concept of pain of Australian children with and without pain: qualitative study. BMJ Open 2019;9:e033199. doi:10.1136/ bmjopen-2019-033199

- Prepublication history for this paper is available online To view these files, please visit the journal online (http://dx.doi. org/10.1136/bmjopen-2019033199).

Poster of one subtheme of the manuscript presented for IASP 2018 in Boston, titled:

"Explaining pain to children with and without pain: what terminology should we use? Qualitative interviews describing pain-related neuroanatomy."

Received 25 July 2019 Revised 01 October 2019 Accepted 02 October 2019

Check for updates

(C) Author(s) (or their employer(s)) 2019. Re-use permitted under CC BY-NC. No commercial re-use. See rights and permissions. Published by BMJ.

${ }^{1}$ Department of Health Professions, Macquarie University, Sydney, New South Wales, Australia

${ }^{2}$ Department of Pain Medicine, Children's Hospital at Westmead, Westmead, New South Wales, Australia

${ }^{3}$ Children's Hospital Westmead Clinical School, The University of Sydney, Sydney, New South Wales, Australia

Correspondence to

Joshua W Pate;

joshua.pate@mq.edu.au

\section{ABSTRACT}

Objective A person's concept of pain can be defined as how they understand what pain actually is, what function it serves and what biological processes are thought to underpin it. This study aimed to explore the concept of pain in children with and without persistent pain.

Design In-depth, face-to-face interviews with drawing tasks were conducted with 16 children (aged 8-12 years) in New South Wales, Australia. Thematic analysis was used to analyse and synthesise the data.

Setting Children with persistent pain were identified from a pain clinic waiting list in Australia, and children without pain were identified through advertising flyers and email bulletins at a university and hospital.

Participants Eight children had persistent pain and eight children were pain free.

Results Four themes emerged from the data: 'my pain-related knowledge', 'pain in the world around me', 'pain in me' and 'communicating my concept of pain'. A conceptual framework of the potential interactions between the themes resulting from the analysis is proposed. The concept of pain of Australian children aged 8-12 years varied depending on their knowledge, experiences and literacy levels. For example, when undertaking a drawing task, children with persistent pain tended to draw emotional elements to describe pain, whereas children who were pain free did not.

Conclusions Gaining an in-depth understanding of a child's previous pain-related experiences and knowledge is important to facilitate clear and meaningful pain science education. The use of age-appropriate language, in combination with appropriate assessment and education tasks such as drawing and discussing vignettes, allowed children to communicate their individual concept of pain.

\section{INTRODUCTION}

Estimates of point prevalence of persistent pain (pain that extends beyond the expected period of healing ${ }^{1}$ ) throughout childhood range from $11 \%$ to $54 \%,{ }^{23}$ which is comparable to that for adults. ${ }^{4}$ Persistent pain in children has detrimental effects on a child's quality of life ${ }^{5}$ and is a significant socioeconomic and health problem. For example, persistent pain in childhood could predict persistent pain in adulthood ${ }^{6}$ and is associated with increased pain-related disability, ${ }^{2}$

\section{Strengths and limitations of this study}

- One strength of this study was the use of drawing tasks and vignettes in the face-to-face interviews as a means of data triangulation.

- Another strength was the large variations in pain experience among the group of 8-12 years old children with persistent pain; some participants had lifelong permanent physical disabilities whereas others had recurrent headaches for just over 1 year, capturing individual variability in pain experiences.

- A limitation of this study is the potential lack of transferability. This study only included children from New South Wales, Australia, who spoke English. It is unknown if the results would be transferable to other cultures and age groups.

- A further limitation is that within the proposed conceptual framework, other influences on a child's concept of pain could exist; however, they were not identified and explored in these interviews.

school absence ${ }^{7}$ poorer reading levels ${ }^{8}$ and emotional distress. ${ }^{9}$ An increasing number of children are being admitted to hospitals for treatment of persistent pain ${ }^{10}$ and health service costs are high. ${ }^{1112}$

Multidisciplinary pain management is currently the gold standard for persistent pain management. ${ }^{13}$ An important part of the multidisciplinary approach is pain science education, aiming to change a person's concept of pain and to improve pain and function by teaching the underlying biopsychosocial mechanisms of pain. ${ }^{14}$ A person's concept of pain can be defined as how they understand "what pain actually is, what function it serves and what biological processes are thought to underpin it ${ }^{15}$; these can be summarised as the 'what, why and how of pain'. Clinically, a range of methods for educational assessments and treatments are used for adults with persistent pain including drawing tasks. ${ }^{16}$ Despite drawing tasks being a robust interview strategy with children, ${ }^{17}$ these methods have not been applied to 
paediatric pain research to investigate a child's concept of pain. ${ }^{18}$

Limited research has been conducted that focuses on a child's concept of pain. For example, children who are pain free have been asked to describe sensations relating to a grazed knee, an injection and a headache. ${ }^{19}$ In addition, pain-specific behaviours, pain quality and pain intensity have been investigated in children with pain. ${ }^{20}$ However, a child's concept of pain, as defined in the previous paragraph, has not been specifically investigated in children with or without persistent pain. Therefore, this remains poorly understood, providing clinicians little guidance on how to provide pain science education to children with persistent pain as part of multidisciplinary management, or to children who are pain free as a strategy to prevent future pain, using language which is clear and unambiguous to a child. The aims of this study were (1) to explore the concept of pain of children diagnosed with persistent pain, and (2) to qualitatively compare the concept of pain between children who have pain with those who are pain free.

\section{METHODS}

All participants' parents provided informed consent prior to participation in the study, and verbal assent was obtained from the participants prior to the commencement of the interview.

\section{Study design}

This qualitative study used one-on-one interviews, lasting approximately $30 \mathrm{~min}$, with children aged 8-12 years. To ensure explicit and comprehensive study reporting, the widely used Consolidated Criteria for Reporting Qualitative Health Research ${ }^{21}$ was implemented. Children were asked to answer questions and complete activities relating to their concept of pain. By adapting grounded theory and using thematic analysis, ${ }^{22}{ }^{23}$ concepts in the transcripts were inductively identified and recorded and then a coding structure was iteratively developed and refined until the aims of the study were achieved. Themes and subthemes were developed from data analysis and synthesis.

\section{Participants}

Two groups of children aged 8-12 years in the state of New South Wales, Australia, were purposefully recruited: children who had persistent pain (greater than 3 months) and children who were pain free and healthy by parent report. Parent report was used to minimise burden on the children being interviewed. The absence, presence and/ or persistence of pain was later confirmed throughout the interviews, allowing opportunity to clarify any discrepancies between reporting. Children were excluded from the study if they (1) had received pain science education from a healthcare professional, (2) were deemed not medically fit to be part of this research study by their treating physician/surgeon or (3) were unable to participate in a 30 min interview based on parent report.

A minimum age for participants was set at 8 years, the youngest age a child can typically self-report and provide meaningful responses in interviews due to their linguistic and cognitive development. ${ }^{24}$ The maximum age of participation was 12 years, an age prior to when abstract thinking capacities typically develop in the teenage years. ${ }^{25}$ The age range was determined to meet a clinical need highlighted by research team members to provide improved assessment and management resources for preteenage children. A pragmatic approach incorporating age limits, rather than a formal assessment of cognitive development or language abilities, allows for direct applicability in time-limited clinical settings.

A purposive selection strategy was used to identify children of varying demographics and pain characteristics who were likely to meet the eligibility criteria. For all children, a mix of gender, age and ethnic backgrounds was sought to capture diversity of experiences. For the children with persistent pain, purposive sampling attended to capturing variations in the duration and location of pain. Children were consecutively identified from The Children's Hospital at Westmead, Australia Complex Pain Service waiting list, and through advertising flyers and email bulletins at Macquarie University and The Children's Hospital at Westmead.

Children were interviewed until data saturation was reached. Data saturation was defined as when no additional new information was attained with additional interviews regarding the final themes. The three researchers analysing the data (JWP, VP and TN) met fortnightly throughout data collection and the thematic analysis to determine when data saturation was reached. Data collection was stopped when all three researchers agreed that saturation had taken place.

\section{Interview script}

An interview script was developed (table 1) to investigate a child's concept of pain based on seven domains (eg, 'How pain works'). These domains were proposed in a recent survey of paediatric pain experts by categorising items from the revised Neurophysiology of Pain Questionnaire $^{26}$ and Explain Pain Target Concepts, ${ }^{27}$ and they were rated as relevant and appropriate. ${ }^{28}$ The interview script aligned with guidelines for interviewing children, ${ }^{29-31}$ and strategies supported by these guidelines were used in the interviews. For example, children were asked to choose their three favourite coloured pens as an icebreaker activity; these pens were then used for the drawing activities. In addition, vignettes with familiar media and cartoon characters were used to increase engagement. ${ }^{32}$ For example, an open-ended question of 'How does pain work?' was followed by a child-friendly cartoon video accessible on YouTube ${ }^{33}$ and children were asked, 'Which body part decides when you will feel pain?'. This question was explained, and clarification of understanding was ensured by asking response-dependent 
Table 1 Example questions, drawing activities and vignettes in the interview script

Questions What do you think pain is?

- What can pain feel like? Any picture words you can think of?

- What do you think happens inside your body for you to feel hurt/sore?

- Or 'how do you think pain is made inside your body?'

- What do you think of when you hear the word 'injury'?

- Can someone be injured but have no pain?

- Can someone have pain but not be injured?

- Where did you learn about that?

- The job of eyes is to see. The job of ears is to hear. The job of the nose is to were to have a job, what do you think the job of pain would be?

-Why does pain last a long time for some people and not for others?

- Do you think pain is always real?

Drawing activities _ I want you to draw whatever the word 'pain' makes you think of.

- Draw where you think your brain, spinal cord and nerves are with three different coloured pencils on the diagram.

Vignettes

- What do you think is happening inside this man's body (cartoon character in a video) when he puts his hand on the stove?

- Why does not his hand just stay on the stove top?

Do you think this cartoon character can have pain without knowing about it? - Or '... without being aware of it?'

- Let us pretend this character has had pain for a long time. If he feels sad, do you think this would change his pain?

- If yes: Do you think his pain would be more/less/bigger/smaller/stronger/quieter?

- How do you think he could make his pain feel different/better/worse?

follow-up questions such as 'What else does your brain do?'.

The team of investigators (including physiotherapists, clinical psychologists and experts in methodology) provided feedback regarding script development. Pilot testing on three healthy pain-free children (aged 7, 8 and 10 years), discussions with education and linguistics experts, and further review by the investigators, resulted in rewording of several questions to ensure that the questions and language were appropriate for children aged 8-12 years. For example, clarifying questions using synonyms (such as 'replace the word 'helpful' with 'useful' if needed', and ask 'What word could we use instead of that?') were incorporated. Following an iterative process, appropriate terminology and language resulting from interviews informed the focus of subsequent interviews until data saturation was reached.

\section{Data collection}

Semistructured interviews were all conducted by JWP (male physiotherapist, a $\mathrm{PhD}$ candidate and no previous relationship with potential participants). To maximise feelings of physical and emotional comfort, interviews took place at a location chosen by the participant (The Children's Hospital at Westmead, Macquarie University, or in participants' homes). Parents/caregivers (from now on referred to as 'parents') were invited to be present for each interview but no questions were asked of them. ${ }^{30}$ Parents were asked not to contribute unless they felt that their child was upset or appeared distressed, at which point the interview was to be terminated and an offer to speak to the clinical psychologist would be made.

A PowerPoint presentation displayed prompts on a laptop screen to guide the discussion. The interviews were audio recorded to enable transcription. Field notes of contextual details and non-verbal expressions were recorded for data analysis and interpretation. For respondent checking, a summary of the interview transcript was provided to families for comment and feedback to enhance the analytical framework, ${ }^{34}$ and a full copy of the transcript was available on request.

A range of demographic characteristics, including age, sex, ethnicity, school year, postcode (for socioeconomic status: using the Australian Socio-Economic Indexes For Areas $(\text { SEIFA })^{35}$ ), parental education level and working status were collected in a demographics questionnaire completed by parents. For children with persistent pain, parent-reported location and duration of pain were also collected before the commencement of the interview.

Data triangulation (using multiple methods to enhance understanding) was achieved by including a drawing task during the interviews. ${ }^{17}$ For this drawing task, children were asked to 'draw whatever the word 'pain' makes you think of'. This follows methodology of a study investigating the concept of death in children. ${ }^{36}$ To explore the language children use to describe components of the nervous system and their familiarity with the anatomical components of this system, a second written task involved labelling a diagram of their nervous system (brain, spinal cord and nerves). ${ }^{37}$ If a child had difficulty with this, 
they were asked to verbally label the diagram, or point to where their own brain, spinal cord and nerves are on their own body.

\section{Analysis}

Audio recordings from interviews were transcribed by JWP verbatim. VP and TN checked transcripts for accuracy. An adapted grounded theory approach ${ }^{23}$ was used to analyse and synthesise the data. Data were independently coded line by line by three researchers (JWP, VP and TN) using NVivo software. ${ }^{38}$ Drawings were thematically analysed by the investigators as has been done in previous research. ${ }^{39} 40$ Analytical themes were inductively developed and fully agreed on by these three researchers through a rigorous iterative process. The themes were scrutinised by a team of subject experts including paediatric clinical psychologists, physiotherapists, academics and methodological experts, in two meetings during the analytical process and one final meeting to attain $100 \%$ consensus.

\section{Public and patient involvement}

Patients were involved in piloting the interview script to identify the most appropriate language to be used in the interviews and the time required to participate. The thematic analysis was directly informed by participants as it was an iterative process. Patients and the general public were not involved in informing other stages of the research process.

\section{RESULTS}

Information sheets were distributed and 16 recruitment emails in total were sent to parents of children who contacted the investigators stating that they wanted to participate. All families replied to the invitation and consented to participate. Therefore, 16 participants, 8 with persistent pain and 8 children who were pain free, were enrolled in the study and completed an interview between October 2017 and February 2018 before data saturation was reached. The median and IQR interview duration was 33 (27-36) min. The three researchers (JWP, VP and TN) coding the transcripts agreed on the correctness of the transcripts, with no disagreements identified.

\section{Participants}

The participants included nine males and seven females, with a median (IQR) age of $10.0(8.8-11.0)$ years. All participants identified themselves as Australian, with seven participants reporting a second ethnicity including Chinese, Lebanese, Indian, Dutch and Eurasian. The median (IQR) Index of Relative Socio-economic Advantage and Disadvantage SEIFA scores (Likert scale of 1-5 rating from disadvantaged to advantaged) was 4 (2.8-5). Of participants with persistent pain, five children in total reported back pain (63\%), two children reported headaches $(25 \%)$ and one child reported neck pain $(13 \%)$. Pain duration ranged from 1 to 10 years with

\begin{tabular}{|c|c|}
\hline Characteristics & n (\%) \\
\hline \multicolumn{2}{|l|}{ Gender } \\
\hline Male & $9(56)$ \\
\hline Female & $7(44)$ \\
\hline \multicolumn{2}{|l|}{ Age (years) } \\
\hline 8 & $4(25)$ \\
\hline 9 & $3(19)$ \\
\hline 10 & $4(25)$ \\
\hline 11 & $3(19)$ \\
\hline 12 & $2(13)$ \\
\hline \multicolumn{2}{|l|}{ Persistent pain } \\
\hline Yes & $8(50)$ \\
\hline \multicolumn{2}{|l|}{ Duration } \\
\hline 0-1 year & $0(0)$ \\
\hline $1-2$ years & $5(63)$ \\
\hline $3-5$ years & $2(25)$ \\
\hline $6-10$ years & $1(13)$ \\
\hline $11+$ years & $0(0)$ \\
\hline \multicolumn{2}{|l|}{ Location } \\
\hline Headache only & $2(25)$ \\
\hline Back only & $2(25)$ \\
\hline Neck only & $1(13)$ \\
\hline Multiple sites & $3(38)$ \\
\hline No & $8(50)$ \\
\hline \multicolumn{2}{|l|}{ Interview setting } \\
\hline Home & $9(56)$ \\
\hline University & $6(38)$ \\
\hline Hospital & $1(6)$ \\
\hline
\end{tabular}

Characteristics may not sum to exactly $100 \%$ due to the effect of rounding.

two participants reporting lifelong permanent physical disabilities. No discrepancies between parent and child reports of the participant's pain history were identified. Table 2 details the demographic characteristics of participants. No participants reported feeling upset or appeared distressed during the interviews.

\section{Key themes}

Four themes emerged from the data: 'my pain-related knowledge', 'pain in the world around me', 'pain in me' and 'communicating my concept of pain'. The first three themes focus on the content that participants conveyed, whereas the fourth theme focuses on the method they used to convey this content. Illustrative quotations for each theme are provided in table 3 .

\section{Theme 1: my pain-related knowledge}

Participant knowledge of the purpose of pain, pain-related anatomy and pain mechanisms varied between 


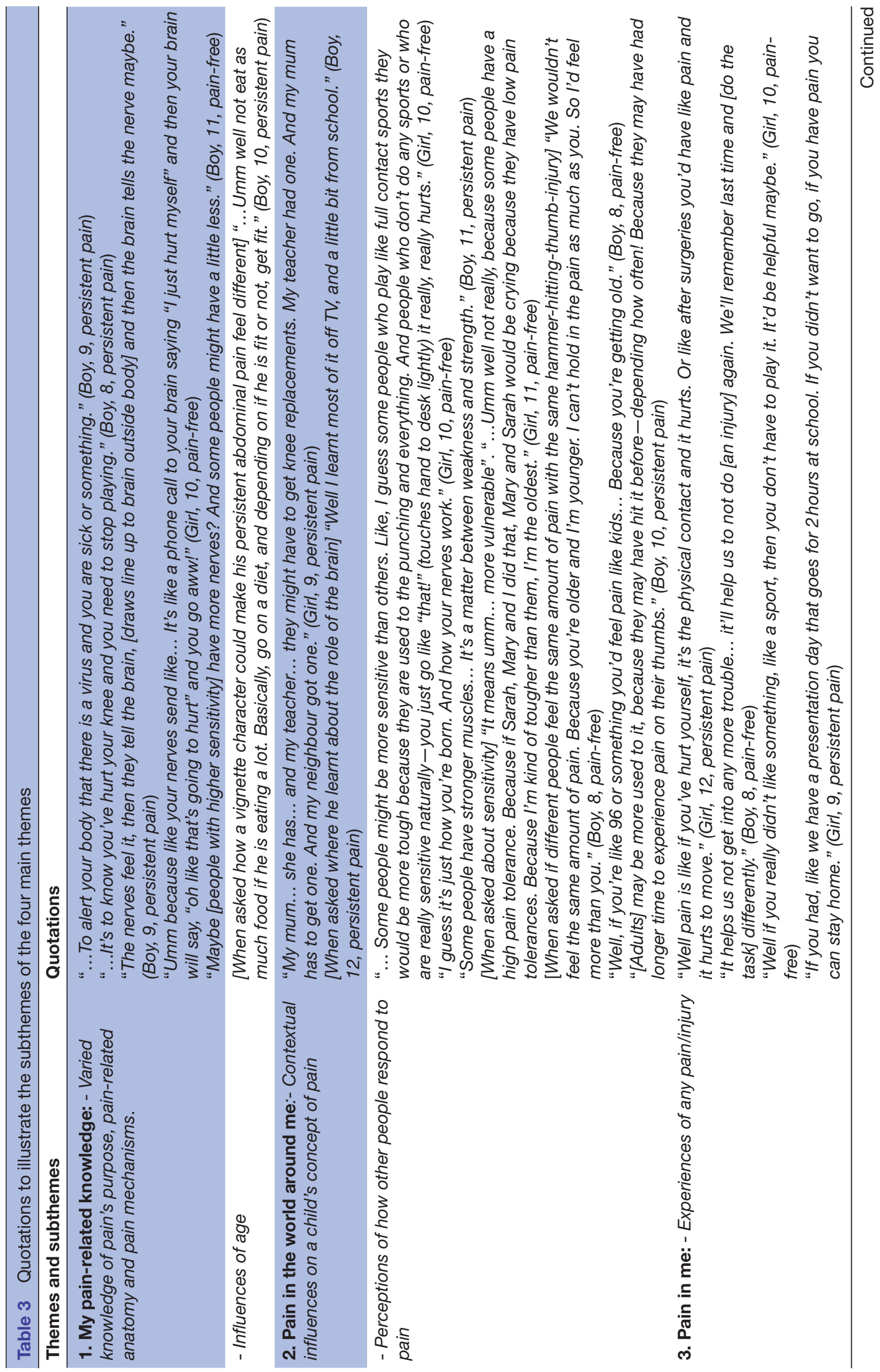




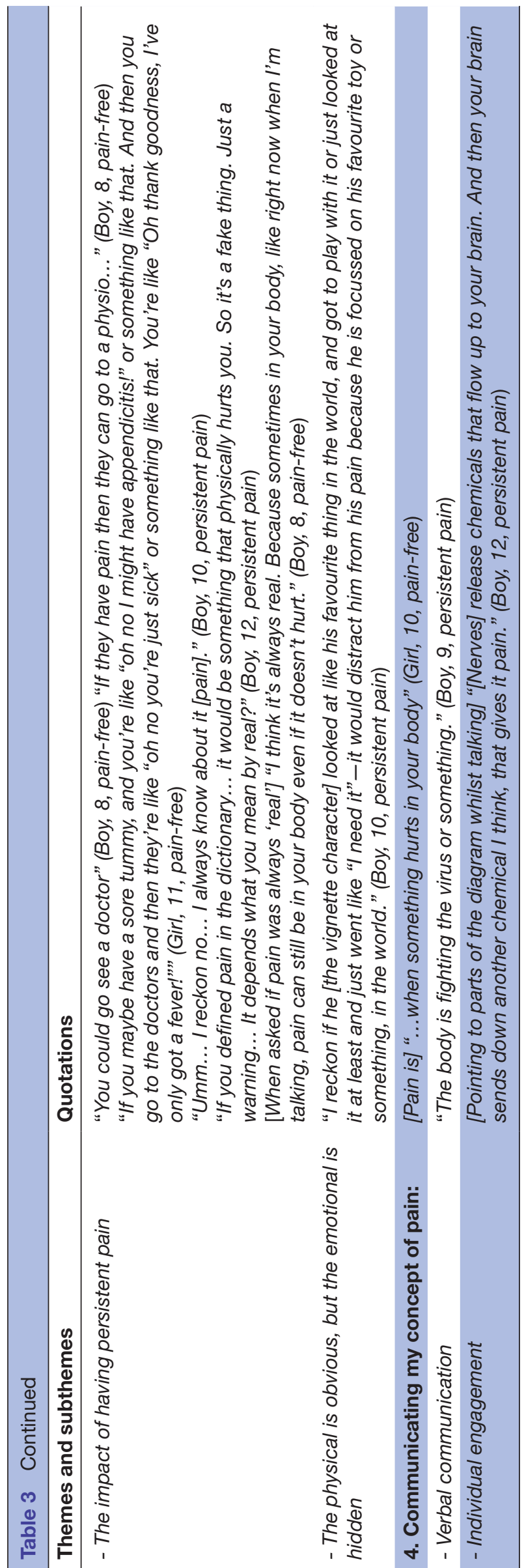

individuals, while participants consistently used concrete terms to describe their pain-related knowledge. Age influenced the participants' ability to express their concept of pain with younger participants responding with uncertainty at times. Based on the thematic analysis, no differences in participant knowledge were identified between participants who had persistent pain and participants who were pain free, nor based on their gender or ethnic background.

Subtheme: varied knowledge of pain's purpose, pain-related anatomy and pain mechanisms

When asked if pain had 'a job in the body', to identify pain's purpose, participants used familiar terms and referred to the idea of pain keeping them safe by protecting, warning, alerting or knowing. The words 'injury' and 'pain' were both commonly associated with the word 'hurt', resulting in some participants expressing confusion about pain's purpose. When asked to 'draw whatever the word "pain" makes you think of', the participants' drawings frequently included an injury (figure 1). Participants used a variety of examples for injuries in their drawings and explanations, such as breaking an arm or leg, having a sprained ankle or having fallen over.

Regarding pain-related anatomy, all participants noted the importance of the brain and correctly labelled the brain inside the head on the diagram (figure 2). A range of understanding was demonstrated in this task and no differences were identified between participants who had persistent pain and participants who were pain free. Participants commonly stated that the brain controls when and how someone feels pain. Exceptions to this were responses that were vague such as 'the head', 'there is no part', or they were unsure. The spinal cord was rarely included when explaining key elements of the nervous system involved in pain; participants frequently drew this in the back disconnected from the brain or were not sure where it was located when questioned. Participants of each age varied in their understanding of the nervous system. Varied understanding of the term 'nerves' was observed; while some participants said that nerves are 'everywhere', others confused nerves with feelings of nervousness and some participants confused nerves with structures such as veins. No child identified interconnections within the nervous system; however, when directly asked, approximately half of each group said the brain, spinal cord and nerves are connected.

Knowledge about pain mechanisms also varied. To explain how pain is experienced, participants frequently reported ideas of 'sending messages' or 'telling the brain'. Metaphors were also used to explain the physiological processes underpinning pain, such as 'it's like a phone call to your brain'. Some participants referred to ideas of sensitivity or pain tolerance to justify that everyone's pain is different. When participants were asked if they would feel the same or different pain if a cartoon character, the investigator (JWP) and the participant all accidentally hit their thumbs with a hammer using the same force, most 

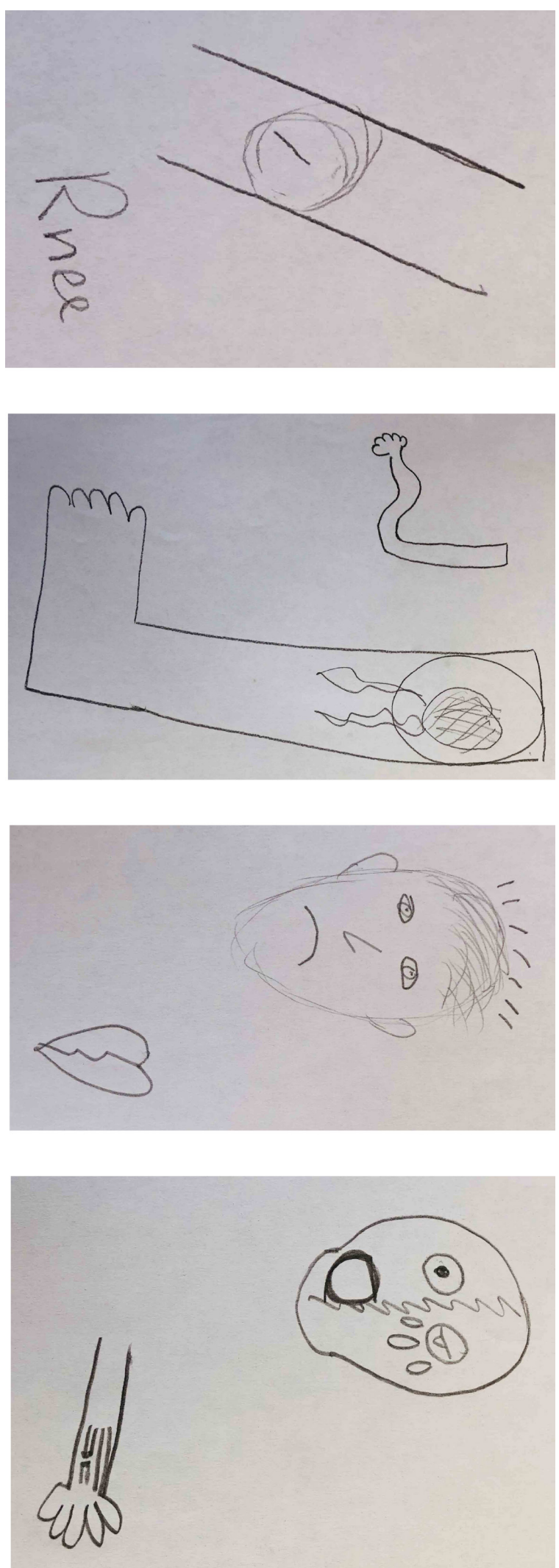

Figure 1 Examples of drawings by children when asked to draw whatever the word 'pain' makes them think of. Panels (a) and (b) represent how children who were pain-free drew injuries (9 years, girl; 10-year girl). Panels (c) and (d) are examples of how children with persistent pain drew more emotional elements such as hearts and tears (11 years, boy; 10 years, girl).
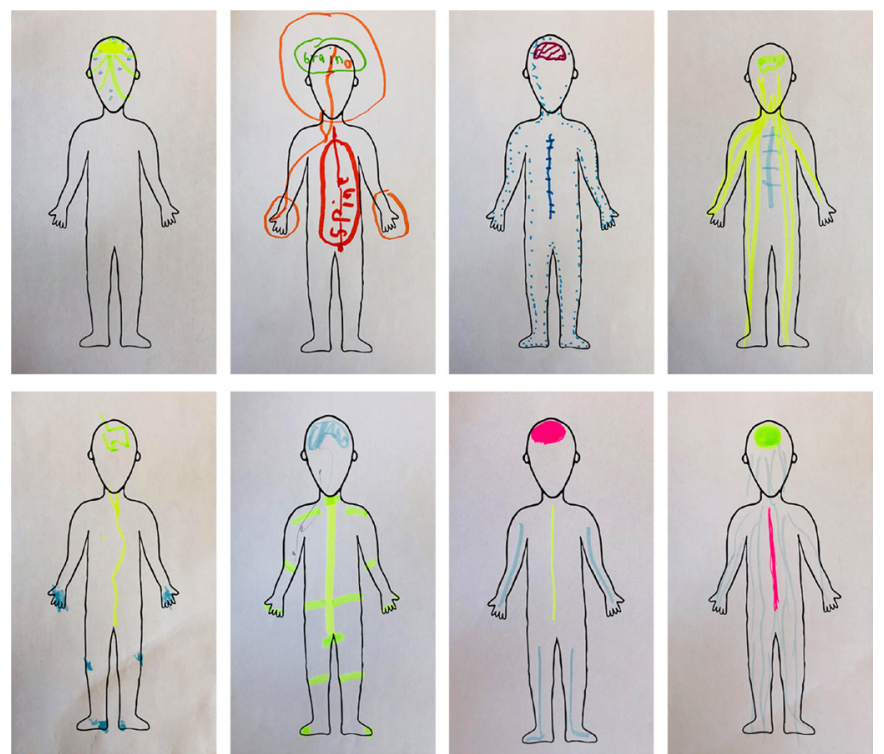

Figure 2 Eight examples of labelled diagrams of the brain, spinal cord and nerves by children aged 8-12 years. The top row shows drawings of children who were pain free $(8$ years, boy; 8 years, boy; 10 years, girl; 11 years, boy) and the bottom row shows drawings of children with persistent pain (8 years, boy; 12 years, boy; 9 years, girl; 11 years, boy). No differences between children with and without persistent pain were identified in this drawing task.

participants identified that each would feel a different pain. Participants provided explanations for this such as being inherently different people, having different levels of 'toughness' or different ages.

\section{Subtheme: influences of age}

Younger participants tended to use simpler terminology. Some participants aged 8 and 9 years more frequently responded 'I don't know' and appeared less confident of their responses, speaking softly when uncertain. In contrast, older participants tended to use more complex terminology, such as phrases like 'physically harming'. All participants in the study appeared to focus more on concrete ideas than on abstract ideas, such as pain having contextual influences. For example, when asked why pain persists for some people and not for others, the most common response was that the person was not caring for an injury correctly.

Participants' understanding of pain-related abstract concepts was influenced by their age, reflecting this age group's stage of cognitive development. Reciting words from a question was seen as distinctly different from understanding a concept. For example, when given a vignette of someone with persisting pain without an injury and asked about pain management strategies, participants responded by suggesting management strategies directly aligned to 'fixing' potential causes of the pain ('not eat as much food if he is eating a lot' and 'depending on if he is fit or not, get fit'-table 3). 


\section{Theme 2: pain in the world around me}

A child's concept of pain is strongly influenced by their environmental and social context, including perceptions of how other people respond to pain. Consequently, differences in the concept of pain between participants with and without persistent pain were evident.

\section{Subtheme: contextual influences on a child's concept of pain}

A child's exposure to family, school and media, appeared to influence their concept of pain, to varying extents between individuals. Participants reported they learnt about pain from family members, particularly parents, as well as at school and via media on television and the internet. To explain various aspects of their concept of pain, participants with persistent pain also used examples of their interactions with health professionals discussing their pain experience despite not having previously received specific pain science education. In contrast, participants who were pain free only used examples of family members and people at school.

\section{Subtheme: perceptions of how other people respond to pain}

Participants with and without persistent pain considered other people to be 'tough' or 'weak' based on their responses to painful experiences. People who felt a lot of pain were perceived by participants as being weaker. People who ignored their pain were perceived as being tougher. The social stigma surrounding pain was also highlighted in phrases describing pain sensitivity. For example, some participants viewed age as a determinant of pain sensitivity, generally stating that 'toughness' increases as a person ages until they 'get old' when it decreases significantly. Other participants considered toughness to be an inherent quality, while others did not and emphasised 'getting stronger' decreases sensitivity to pain.

\section{Theme 3: pain in me}

A child's concept of pain was based on their individual experiences with pain and injury. All participants clearly described physical aspects of pain, whereas emotional aspects were relatively hidden and were revealed only by participants with persistent pain on further verbal probing or drawing tasks. The impact of persistent pain was highly individualised and related deeply to their past experiences.

\section{Subtheme: experiences of any pain/injury}

Participants with and without persistent pain explained their concept of pain by using examples of pain and injury from their own experiences. Regarding the purpose that pain serves, most participants reported that pain is sometimes a helpful thing to feel. The most common reason for this was a warning to avoid further problems; however, two participants (one with persistent pain and one without) described the idea of pain being helpful to avoid attending something deemed boring or undesirable such as 'a sport' or 'presentation day'.
Subtheme: the impact of having persistent pain

Participants with persistent pain expressed different aspects of their concept of pain compared with participants without pain, with these aspects being dependent on their individual pain experiences. Participants with persistent pain considered broader aspects of the pain experience when describing what 'pain' is, such as the impact of surgery, effects of feelings, the idea of healing and the diverse influences of health professionals.

When participants were provided with a vignette and asked if a character could have pain without knowing about it, participants were generally uncertain with some responding purely based on their own experience without reference to the vignette. There appeared to be a difference in explanations between participants with and without persistent pain; participants who were pain free responded with regards to the vignette only whereas participants with persistent pain used the vignette with reference to their own personal experience.

Participants with persistent pain focused more on emotional aspects of pain than participants who were pain free. When undertaking a drawing task, participants with persistent pain tended to draw emotional elements to describe pain, whereas participants who were pain free did not (figure 1). Some participants were confused when questioned about aspects of their drawing that illustrated emotional pain, mental pain or nightmares, and were unable to verbally communicate how these types of pain related to a person's overall pain experience.

Further investigating what children think pain is, the discussion around 'Is pain real?' varied between participants with and without persistent pain. While some participants in both groups described some confusion around the term 'real' when asked this question, most participants with persistent pain said that pain is not always real. In contrast, most participants who were pain free said that pain is always real. Having persistent pain appeared to influence views on the 'reality' of pain.

Subtheme: the physical is obvious, but the emotional is hidden Participants tended to focus their discussions on physical and visible components of pain-related processes. The most obvious example of this was mentioned previously; that participants without persistent pain did not draw emotional elements of pain.

When participants discussed possible mechanisms for how different factors can influence pain, most participants with persistent pain considered their experiences and stated that they could use self-taught management techniques, such as distracting themselves from pain by listening to music. In stark contrast, participants who were pain free did not mention cognitive strategies such as distraction. Other than attentional strategies, participants did not mention any other factors that can influence the experience of pain. All children interviewed appeared unsure about the possible influence of other senses on pain, for example, visual input. 


\section{Theme 4: communicating my concept of pain}

Participants used verbal descriptions, drawings and diagrams to describe their concept of pain with drawing tasks and vignettes aiding some participants' communication during the interviews. No differences in the use of these methods of communicating were identified between participants who had persistent pain and participants who were pain free.

\section{Subtheme: verbal communication}

Participants' verbal descriptions of their concept of pain were individual and varied. For example, some participants described the physiological processes underpinning pain using terms such as 'chemicals' whereas others used terms such as 'virus' and 'disease'. The words 'pain', 'injury' and 'hurt' were used interchangeably by multiple participants. No differences between groups were identified for this transposable use of terms.

\section{Subtheme: individual engagement}

The value of the drawing tasks and vignettes appeared to relate to levels of engagement with the task, and this value did not appear related to age, gender or ethnic background. The drawing task was very helpful in enabling some participants to articulate thoughts they had not verbally communicated. Asking the follow-up question, 'why did you draw that?' gave participants an opportunity to expand on their thoughts. For example, some participants did not draw anything when first asked, but later drew representations, such as a face with tears. In contrast, four participants did not like the drawing task and did not feel comfortable with this activity, preferring to speak about it and leaving the drawing page mostly blank (8 years, boy, pain free; 12 years, boy, persistent pain; 11 years, girl, pain-free; 8 years, boy, pain free).

\section{Proposed conceptual framework}

The potential interactions between the themes resulting from the analysis and a child's concept of pain form a proposed conceptual framework that is visually presented in figure 3 .

The first three themes are inputs and combine in varying proportions to produce the output which is how a child communicates their concept of pain.

\section{DISCUSSION}

This study is the first known to the authors to investigate a child's concept of what pain is, why it exists and how it is experienced. The primary objective of this study was to gain insight into the way that children aged 8-12 years, who have not received pain science education, conceptualise pain. Four themes emerged from the data: my pain-related knowledge, pain in the world around me, pain in me and communicating my concept of pain. Participants' communication of their concept of pain was based on their individual knowledge and experience. Participants with persistent pain considered broader

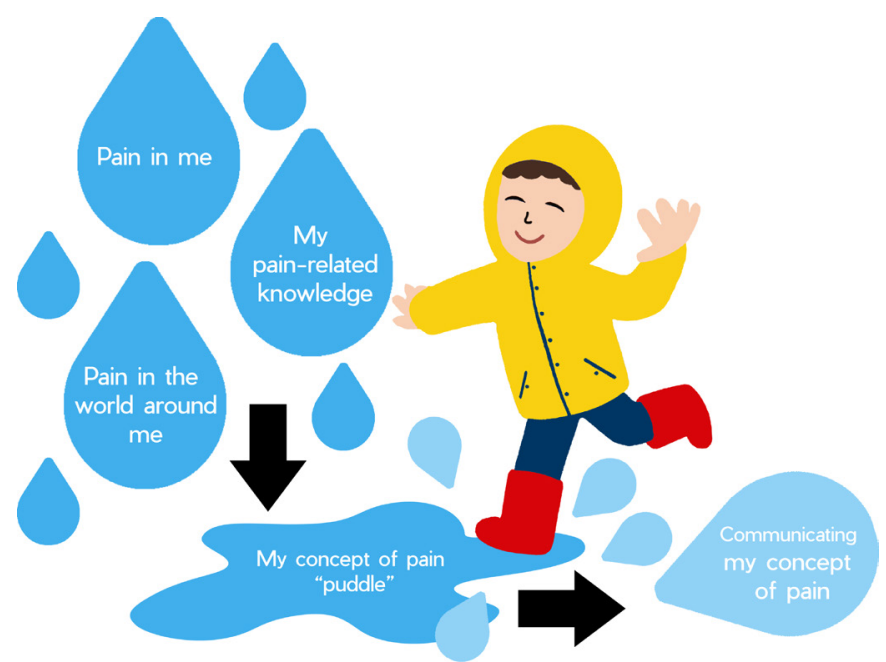

Figure 3 A proposed conceptual framework of the potential interactions between the themes resulting from the analysis and a child's concept of pain.

aspects of pain and focused more on emotional impacts and influences than participants who were pain free.

Children's experiences of pain have previously been reported in qualitative studies. As examples, one study considered children's descriptions of types of pain, ${ }^{19}$ another focused on painful experiences, ${ }^{41}$ another on children's pain-related vocabulary ${ }^{42}$ and a recent study of children aged 10-18 years with neuropathic pain considered personal pain experiences and language used. ${ }^{43}$ Similarly in studies of adults, pain experiences have been explored. ${ }^{44} 45$ These studies differed from the present study in that the focus was on the experience of pain, rather than a person's concept of pain. Children's conceptual frameworks have been studied using drawings with the concept of death, ${ }^{36}$ but the present study is the first to apply drawing methodology to investigate the concept of pain. Metaphors and explanations about pain that clinicians use with children have been discussed in the literature, ${ }^{46}$ but the metaphors and explanations that children themselves use have not been explored.

Using the conceptual framework in figure 3, several important issues are raised for future research regarding clinical practice. First, it is currently unknown the extent to which each of the themes impacts on a child's concept of pain. Does a child's experience have more of an impact on their concept of pain than the impact of their knowledge or emotions? The relative size of each 'raindrop' is not yet known. Nonetheless, the extent to which each theme influences a child's concept of pain is likely to be highly idiosyncratic, differing from one child to another and also changing over time. Second, it is unknown if other factors contribute to the composition of the puddle. The 'blank' raindrops in figure 3 highlight that, for an individual child, there could be other factors involved that were not identified in these interviews. Third, how can changes in a child's concept of pain 'puddle' be assessed? Conceptual change theory ${ }^{47}$ suggests that the 'puddle' can theoretically change with 
education; however, no research exists to confirm this. A child's concept of pain assessment tool would be required to investigate this further. Further research would also be required to explore whether the findings relate to children below the age of 8 years, adolescents, adults and non-English speaking populations.

A key principle of clinical practice requiring future exploration is how patient care is appropriately tailored and individualised based on a child's concept of pain. The language and other communication tools used in this study may be useful for assessing a child's concept of pain prior to pain science education, to ensure care is individualised based on identified needs. ${ }^{48} 49$ The helpfulness of using a variety of media (eg, drawings, videos and text) appeared to relate more to a child's level of comfort with the medium or level of engagement, rather than their age. Therefore, as part of a flexible approach to communicating with children, using a range of media is recommended. In particular, drawings can provide more information and/or more accurate information compared with narrative methods, and they can increase comfort, facilitate memory retrieval and help children organise verbal reports. ${ }^{5051}$ Both the open-ended drawing and the diagram-labelling task provided helpful information and enhanced other verbal responses in this study. Several participants commented that they enjoyed discussing the vignettes provided, which supports the established benefits of using vignettes clinically and in qualitative research. ${ }^{52} 53$ Because a child's concept of pain is not always overtly communicated by the child, particularly the 'hidden' emotional components which affect communication, ${ }^{54}$ using vignettes and drawings in pain science education or assessments may be particularly beneficial in clinical practice. In addition to these future clinical directions, exploring the effects of different pain durations and pain diagnoses on a child's focus on emotional aspects of pain is warranted.

A further potential clinical implication is that a more flexible and individualised assessment of a child's concept of pain could directly inform what pain science education is likely to be most beneficial for a child. Pain science education for adults is based on conceptual change theory where the assumption is that misconceptions exist. ${ }^{15}$ The results of the current study show that complex concepts are still developing in childhood, and so pain science education for children should also incorporate educational approaches where concepts are taught with gradually increasing complexity built on previous conceptual development. ${ }^{55}$ Tailored, individualised pain science education, specifically aimed at addressing the different variables that have made up an individual child's concept of pain 'puddle' (figure 3), appears warranted. Unexplored variables may be impacting on a child's concept of pain, such as their intellectual and emotional intelligence, their general attitude, fears, social circumstances, perspectives on 'toughness' and other aspects of their history. Each individual child may benefit from tailored education provided in different ways. Some children may not require any formal pain science education, but rather benefit most from reassurance from a trusted adult with influence such as a parent ${ }^{56}$ teacher or health professional. Education deemed too complex by a child may result in misunderstanding and fear, ${ }^{57}$ which could potentially aid in the development and/or maintenance of persistent pain and disability. ${ }^{589}$

The terminology and understanding of neuroanatomy used in descriptions of a child's concept of pain are also important given the use of neuroanatomical terms in pain science education. ${ }^{14}{ }^{15}$ In the current study, children typically conceptualised the nervous system without inclusion of the spinal cord and considered it to have two parts; the brain and a peripheral component, and uncertainty existed regarding how these two parts are connected. Phrases, such as 'spinal cord', 'nerves' and 'real', are likely to be poorly understood and potentially misinterpreted by children. Participants appeared to grasp the concept of the brain receiving warning messages and, based on these messages and many other factors, producing pain to keep the body safe. It is critical to carefully consider language when discussing pain with children, ${ }^{42}$ as younger participants in this age group tended to only use and understand simpler terminology. Age-appropriate language used in conversations by health professionals may facilitate the therapeutic alliance. For example, if a child uses a particular word or phrase to describe their concept of pain, a patient-centred empathetic communication strategy ${ }^{60}$ would be for the clinician to incorporate the child's language in the discussion rather than using technical terms. In addition, the apparent lack of awareness regarding how sensory input and distraction can influence pain provides some support for educating children at an age-appropriate level about biological mechanisms underpinning pain.

This study has several strengths and limitations. One strength of this study was the use of drawing tasks and vignettes in the face-to-face interviews as a means of data triangulation. ${ }^{61}$ Another strength was the large variations in pain experience among the group of 8-12 year old participants with persistent pain; some participants had lifelong permanent physical disabilities whereas others had recurrent headaches for just over 1 year, capturing individual variability in pain experiences. ${ }^{62}$ A limitation of this study is the potential lack of transferability. This study only included children from New South Wales, Australia, who spoke English. It is unknown if the results would be transferable to other cultures and age groups. A further limitation is that other 'raindrops' in the proposed conceptual framework could exist that were not identified and explored in these interviews and would be suitable to investigate in future research.

In conclusion, Australian children aged 8-12 years who have not received formal pain science education had concepts of pain that depended on a child's knowledge and experiences. The importance of gaining an in-depth understanding of a child's previous pain-related experiences and knowledge is emphasised, to facilitate clear and 
meaningful pain science education. The use of age-appropriate language, in combination with assessment and education tasks such as drawing and discussing vignettes, allowed participants with persistent pain to communicate their individual concept of pain. Future research quantitatively assessing a child's concept of pain is needed to improve and target pain science education for children with pain.

\section{Twitter Joshua W Pate @JoshuaWPate}

Acknowledgements The authors thank all the children and their families for their openness and for giving their valuable time, energy and efforts to participate in this study. They also acknowledge Natasha Haynes, Nurse Practitioner from The Children's Hospital at Westmead Pain Team, who helped to recruit participants and supported the study.

Contributors Conception and design: all authors. Planning and implementation: all authors. Data collection: JWP. Coding data for thematic analysis: JWP, TN and VP. Analysis and interpretation: all authors. Drafting the article: JWP. Review and editing: all authors. Overall responsibility: JWP under the supervision of VP, JH and $\mathrm{MH}$.

Funding JWP is a Ph.D. Student funded by a Macquarie University Research Training Program (RTP) full-time scholarship.

Competing interests None declared.

Patient consent for publication Not required.

Ethics approval The study was approved by the Human Research Ethics Committees of Sydney Children's Hospital Network (Ref: LNR/17/SCHN/268) and Macquarie University (Ref: 5201700820).

Provenance and peer review Not commissioned; externally peer reviewed.

Data availability statement Deidentified transcripts and drawings, and the unpublished protocol, will be made available upon reasonable request from Joshua Pate (https://orcid.org/0000-0002-1049-3916) until 2024 as per ethical approval. Reuse without ethical approval is not permitted. A data-sharing agreement will require a commitment to using the data only for specified research purposes, to securing the data appropriately and to destroying the data after a nominated period.

Open access This is an open access article distributed in accordance with the Creative Commons Attribution Non Commercial (CC BY-NC 4.0) license, which permits others to distribute, remix, adapt, build upon this work non-commercially, and license their derivative works on different terms, provided the original work is properly cited, appropriate credit is given, any changes made indicated, and the use is non-commercial. See: http://creativecommons.org/licenses/by-nc/4.0/.

ORCID iD

Joshua W Pate http://orcid.org/0000-0002-1049-3916

\section{REFERENCES}

1 Friedrichsdorf S, Giordano J, Desai Dakoji K, et al. Chronic pain in children and adolescents: diagnosis and treatment of primary pain disorders in head, abdomen, muscles and joints. Children 2016;3:42.

2 King S, Chambers CT, Huguet A, et al. The epidemiology of chronic pain in children and adolescents revisited: a systematic review. Pain 2011;152:2729-38.

3 Swain MS, Henschke N, Kamper SJ, et al. An international survey of pain in adolescents. BMC Public Health 2014;14:447.

4 Access Economics. The high price of pain: the economic impact of persistent pain in Australia. Sydney: MBF Foundation, 2007: 9-11.

5 Hunfeld JA, Perquin CW, Duivenvoorden HJ, et al. Chronic pain and its impact on quality of life in adolescents and their families. J Pediatr Psychol 2001;26:145-53.

6 Hassett AL, Hilliard PE, Goesling J, et al. Reports of chronic pain in childhood and adolescence among patients at a tertiary care pain clinic. J Pain 2013;14:1390-7.

7 Lisman-van Leeuwen Y, Spee LAA, Benninga MA, et al. Prognosis of abdominal pain in children in primary care--a prospective cohort study. Ann Fam Med 2013;11:238-44.

8 Kosola S, Mundy LK, Sawyer SM, et al. Pain and learning in primary school: a population-based study. Pain 2017;158:1825-30.
9 Zernikow B, Wager J, Hechler T, et al. Characteristics of highly impaired children with severe chronic pain: a 5-year retrospective study on 2249 pediatric pain patients. BMC Pediatr 2012;12:54.

10 Coffelt TA, Bauer BD, Carroll AE. Inpatient characteristics of the child admitted with chronic pain. Pediatrics 2013;132:e422-9.

11 Groenewald CB, Essner BS, Wright D, et al. The economic costs of chronic pain among a cohort of treatment-seeking adolescents in the United States. J Pain 2014;15:925-33.

12 Mahrer NE, Gold JI, Luu M, et al. A cost-analysis of an interdisciplinary pediatric chronic pain clinic. J Pain 2018;19:158-65.

13 Kamper SJ, Apeldoorn AT, Chiarotto A, et al. Multidisciplinary biopsychosocial rehabilitation for chronic low back pain: cochrane systematic review and meta-analysis. BMJ 2015;350:h444.

14 Harrison LE, Pate JW, Richardson PA, et al. Best-Evidence for the rehabilitation of chronic pain Part 1: pediatric pain. $J$ Clin Med 2019;8.

15 Moseley GL, Butler DS. Fifteen years of explaining pain: the past, present, and future. J Pain 2015;16:807-13.

16 Louw A, Zimney K, Puentedura EJ, et al. The efficacy of pain neuroscience education on musculoskeletal pain: a systematic review of the literature. Physiother Theory Pract 2016;32:332-55.

17 Driessnack M. Children's Drawings as facilitators of communication: a meta-analysis. J Pediatr Nurs 2005;20:415-23.

18 Robins H, Perron V, Heathcote L, et al. Pain neuroscience education: state of the art and application in pediatrics. Children 2016;3:43.

19 Harbeck C, Peterson L. Elephants dancing in my head: a developmental approach to children's concepts of specific pains. Child Dev 1992;63:138-49.

20 Jacobson CJ, Kashikar-Zuck S, Farrell J, et al. Qualitative evaluation of pediatric pain behavior, quality, and intensity item candidates and the PROMIS pain domain framework in children with chronic pain. $J$ Pain 2015;16:1243-55.

21 Tong A, Sainsbury P, Craig J. Consolidated criteria for reporting qualitative research (COREQ): a 32-item checklist for interviews and focus groups. Int J Qual Health Care 2007;19:349-57.

22 Kvale S. InterViews. Thousands Oaks: CA: Sage, 1996.

23 Liamputtong P. Qualitative research methods. 3rd ed. Australia: Oxford University Press, 2009.

24 Arbuckle R, Abetz-Webb L. "Not just little adults": qualitative methods to support the development of pediatric patient-reported outcomes. Patient 2013;6:143-59.

25 Christie D, Viner R. Adolescent development. BMJ 2005;330:301-4.

26 Catley MJ, O'Connell NE, Moseley GL. How good is the neurophysiology of pain questionnaire? A Rasch analysis of psychometric properties. J Pain 2013;14:818-27.

27 Butler D, Moseley G. Explain pain supercharged. Adelaide City West, 2017.

28 Pate J, Hush J, Hancock M, et al. A child's concept of pain: an international survey of pediatric pain experts. Children 2018;5:12.

29 Docherty S, Sandelowski M. Focus on qualitative methods: interviewing children. Res Nurs Health 1999;22:177-85.

30 Lobe B, Livingstone S, Olafsson K, et al. Best practice research guide: how to research children and online technologies in comparative perspective. EU Kids Online, 2008.

31 Kortesluoma R-L, Hentinen M, Nikkonen M. Conducting a qualitative child interview: methodological considerations. J Adv Nurs 2003;42:434-41.

32 Ritchie J, Lewis J, Nicholls CM. Qualitative research practice: a guide for social science students and researchers. Sage, 2013.

33 TED-Ed. How does your brain respond to pain? - Karen D. Davis. 2014. YouTube (2:24 - 2:26). Available: https://www.youtube.com/ watch?v=17wfDenj6CQ [Accessed 1 Oct 2017].

34 Popay J, Rogers A, Williams G. Rationale and standards for the systematic review of qualitative literature in health services research. Qual Health Res 1998;8:341-51.

35 Pink B. Census of Population and Housing: Socio-Economic Indexes for Areas (SEIFA), Australia, 2011. In: Technical paper. Australian Bureau of Statistics (ABS). Canberra: Australian Government, 2011: 54-8.

36 Bonoti F, Leondari A, Mastora A. Exploring children's understanding of death: through drawings and the death concept questionnaire. Death Stud 2013;37:47-60.

37 Buckley CA, Waring MJ. Using diagrams to support the research process: examples from grounded theory. Qualitative Research 2013;13:148-72.

38 QSR International Pty Ltd. NVivo qualitative data analysis software (version 9. Australia: QSR International Pty Ltd Doncaster, Vic, 2006.

39 Tamm ME, Granqvist A. The meaning of death for children and adolescents: a phenomenographic study of Drawings. Death Stud 1995;19:203-22. 
40 Angell C, Alexander J, Hunt JA. 'Draw, write and tell': a literature review and methodological development on the 'draw and write' research method. Journal of Early Childhood Research 2015;13:17-28.

41 Ely EA. The experience of pain for school-age children: blood, bandaids, and feelings. Children's Health Care 1992;21:168-76.

42 Johnson E, Bornman J, Tönsing KM. An exploration of pain-related vocabulary: implications for AAC use with children. Augment Altern Commun 2016;32:249-60.

43 Yeung K-K, Engle L, Rabel A, et al. It just feels weird!: a qualitative study of how children aged 10-18 years describe neuropathic pain. Disabil Rehabil 2017;39:1695-702.

44 Bunzli S, Watkins R, Smith A, et al. Lives on hold: a qualitative synthesis exploring the experience of chronic low-back pain. Clin $J$ Pain 2013:29:907-16.

$45 \mathrm{Sim} J$, Madden S. Illness experience in fibromyalgia syndrome: a metasynthesis of qualitative studies. Soc Sci Med 2008;67:57-67.

46 Coakley R, Schechter N. Chronic pain is like... the clinical use of analogy and metaphor in the treatment of chronic pain in children. Pediatric Pain Letter 2013;15:1-8.

47 Posner GJ, Strike KA, Hewson PW, et al. Accommodation of a scientific conception: toward a theory of conceptual change. Sci Educ 1982;66:211-27.

48 Celedon X, Amari A, Ward CM, et al. Children and adolescents with chronic pain and functional disability: use of a behavioral rehabilitation approach. Curr Phys Med Rehabil Rep 2014;2:86-92.

49 Williams G, Howard RF, Liossi C. Persistent postsurgical pain in children and young people: prediction, prevention, and management. Pain Rep 2017;2.

50 Gross J, Hayne H. Drawing facilitates children's verbal reports of emotionally laden events. J Exp Psychol 1998;4:163-79.
51 Liamputtong P, Fernandes S. What makes people sick?: the drawing method and children's conceptualisation of health and illness. Aust $J$ Early Child 2015;40:23-32.

52 Barter C, Renold E. 'I wanna tell you a story': exploring the application of vignettes in qualitative research with children and young people. Int J Soc Res Methodol 2000;3:307-23.

53 Jenkins N, Bloor M, Fischer J, et al. Putting it in context: the use of vignettes in qualitative interviewing. Qualitative Research 2010;10:175-98.

54 Hadjistavropoulos T, Craig KD, Duck S, et al. A biopsychosocial formulation of pain communication. Psychol Bull 2011;137:910-39.

55 Novak JD, Cañas AJ. The theory underlying concept maps and how to construct and use them. Pensacola: Institute for Human and Machine Cognition, 2008.

56 Evans S, Tsao JCl, Lu Q, et al. Parent-Child pain relationships from a psychosocial perspective: a review of the literature. J Pain Manag 2008;1:237-46.

57 Simons LE, Kaczynski KJ. The fear avoidance model of chronic pain examination for pediatric application. J Pain 2012;13:827-35.

58 Zale EL, Ditre JW. Pain-Related fear, disability, and the fearavoidance model of chronic pain. Curr Opin Psychol 2015;5:24-30.

59 Vlaeyen JWS, Crombez G, Linton SJ. The fear-avoidance model of pain. Pain 2016;157:1588-9.

60 Linton SJ, Flink IK, Nilsson E, et al. Can training in empathetic validation improve medical students' communication with patients suffering pain? A test of concept. Pain Rep 2017;2:e600.

61 Krefting L. Rigor in qualitative research: the assessment of trustworthiness. Am J Occup Ther 1991;45:214-22.

62 Denk F, McMahon SB. Neurobiological basis for pain vulnerability: why me? Pain 2017;158:S108-14. 